Facundo, entre

la naturaleza y la

condición humana

Lic. Adrián Rocha. 


\section{Facundo, entre la naturaleza y la condición humana}

Lic. Adrián Rocha.

Licenciado en Ciencias Politicas.

Universidad Abierta Interamericana, UAI. https://orcid.org/0000-0003-0538-0316

Adrianhrocha86@gmail.com

Recibido: 20 de marzo 2018

Aceptado: 23 de mayo 2018

\section{Facundo, between nature and the human condition}

(C) \$( ) Copyright $\odot 2018$ UNAN-Managua

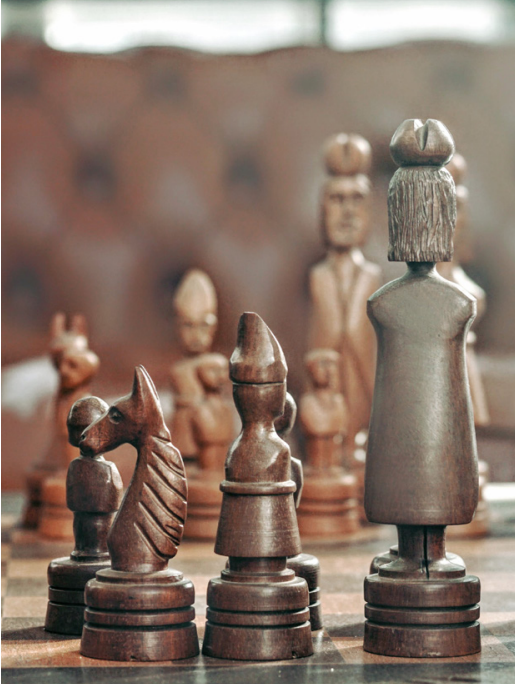

\section{PALABRAS CLAVE}

Sarmiento - Argentina - FacundoEnsayo.

\section{KEY WORDS}

Sarmiento - Argentina - FacundoEssay.
This essay analyzes the way in which Domingo Faustino Sarmiento perceives the "civilization and barbarism" dichotomy. In this sense, the Argentinian statesman enters into a geographical, cultural and political study of the figure of Facundo Quiroga, which reflects his fascination not only with the character, but with what he represents. Thus, the culture and nature of that representation appear to Sarmiento as an obstacle that, if it is necessary, must be overcome to establish the Nation State. 


\section{Introducción}

$\mathrm{E}$

ste ensayo se centra en la manera en que Domingo Faustino Sarmiento percibe la dicotomía "civilización y barbarie". En ese sentido, el mandatario argentino se adentra en un estudio geográfico, cultural y político de la figura de Facundo Quiroga, que refleja su fascinación no solamente para con el personaje, sino con lo que éste representa. Así, la cultura y la naturaleza de esa representación aparecen para Sarmiento como un obstáculo que, de ser necesario, debe ser sorteado para establecer el Estado Nación. El objetivo de estas reflexiones es indagar en cómo el mando siempre se construye sobre la base de premisas estéticas, filosóficas y culturales, y persistir, entonces, en la siempre dudosa pero latente cuestión que existe en torno de la existencia, o no, de la naturaleza humana

\section{Mímesis entre naturaleza y elementos sociales: reconocimiento por medio de la fuerza y fascinación estética por la cultura no civilizada}

Escribir sobre Facundo implica, en un registro inicial, adentrarse en las problemáticas inherentes a la organización nacional. Ese adentramiento, por su parte, induce a reflexionar acerca de los tópicos clásicos del drama decimonónico de la política argentina: la extensión territorial, "el mal que aqueja a la Argentina ${ }^{1}$ ", la búsqueda de un poder centralizado (bajo diferentes modalidades y propuestas); la guerra civil, el monopolio legítimo de la fuerza, en fin, la creación de un estado nacional.

Estos elementos conforman ineludiblemente el mapa de los problemas que en la superficie del análisis sarmientino se presentan cruda y vivamente delineados, pero también subyace al mismo un discusión más profunda respecto de la condición humana y de su vínculo con la naturaleza o el medio geográfico. Si bien es cierto que la cuestión del relacionamiento entre la tiranía, la geografía, las costumbres y el "asiatismo" bárbaro ya ha sido planteada por otros autores $^{2}$, lo que aquí interesa destacar es el desdibujamiento al que por momentos se asiste en Facundo entre la descripción de caracteres humanos y detalles naturales; disolución que difusamente se afinca en el hombre cuando el autor describe con ahínco aspectos humanos que intencionadamente busca señalar, y en la naturaleza cuando analiza aspectos propios de un medio geográfico que, según su interpretación, posee las mismas cualidades que le endilga al elemento social que en él habita.

Si lo humano y lo natural se desdibujan en la lectura que Sarmiento hace de la Barbarie, es porque su análisis está provisto de una hermeneusis cultural de la cual es plausible extraer interpretaciones que, paradójicamente, sugieren la dificultad de integrar la barbarie, tal como la piensa Sarmiento, al ideario civilizatorio que él vislumbra para la Argentina; excepto que éste se implemente por medio de la violencia y de métodos que en el mismo texto son considerados como propios de aquélla:

Asi es como en la vida argentina empieza a establecerse por estas peculiaridades el predominio de la fuerza brutal, la preponderancia del más fuerte, la autoridad sin límites $y$ sin responsabilidad de los que mandan, la justicia administrada sin formas y sin debate ${ }^{3}$.

1- Sarmiento, D.F., Facundo, civilización y barbarie, M. Alfredo Angulo Editor, Buenos Aires, Colección “Letras de Oro", pág. 6. En adelante, las citas correspondientes a Facundo remitirán todas a esta edición.

2 -Entre ellos, cabe destacar los trabajos de Ana María Barrenechea y Carlos Altamirano, respectivamente. En el caso de ella, el énfasis está puedo en las campañas pastoras, la estética romántica, la figura del gaucho, La Pampa y el uso del cuchillo. En el caso de Altamirano, la cuestión del "asiatismo" está trabajada en profundidad, en diálogo con el ensayo de Ricardo Piglia.

3- Sarmiento, D.F. op. cit. Pág. 11-12. 
Estas cualidades se encuentran aunadas en el cuadro de la barbarie que Sarmiento traza, allí donde "la naturaleza salvaje dará la ley por mucho tiempo y la civilización permanecerá débil e ineficaz ". . Más adelante, se volverá sobre la cita que destaca que la justicia se administra "sin formas y sin debate", porque en ella hay varias aristas a tratar.

Este constante juego de integración y desintegración de la condición humana y la condición natural constituye un hilo invisible que atraviesa todo el libro, y da cuenta de que si bien la preocupación de Sarmiento aparece cifrada bajo el diagnóstico político e institucional, en su anverso se manifiesta como filosófica y cultural. Aunque no sería erróneo preguntarse si esa latencia filosófica no es, a su vez, un modo "profundo" de legitimar un discurso político, o si, por el contrario, ese discurso no sería un modo vigoroso y espectacular de manifestar una inquietud filosófica y cultural que Sarmiento descubriría como causalidad decisiva del drama nacional. Ni una ni otra parece explicar por sí misma la cuestión.

En lo que sigue, se intentará demostrar que esta disyuntiva constituye una simplificación, y que, por añadidura, la dicotomía entre civilización y barbarie plantea un conflicto que no debería explicarse por una lógica de exclusiones, aunque así fuera usufructuada políticamente por Sarmiento.

\section{Reflexión}

Si partimos de la aceptación de que la dicotomía "civilización y barbarie ${ }^{5}$ " no funciona en el análisis de Sarmiento necesariamente como un sistema de exclusiones, sino que opera mediante una lógica que, en efecto, es binaria, pero cuyos componentes jamás logran excluirse definitivamente (y allí reside precisamente el drama, ya que ninguna termina por vencer completamente a la otra, para el momento en que Sarmiento escribe fragmentariamente este trabajo), entonces debe descartarse el planteamiento maniqueo, debido a que ni el discurso político busca legitimarse en el trasfondo filosófico, ni éste pretende encubrirse a través de aquél, aunque esté clara la posición política de Sarmiento.

Civilización y barbarie significan dos condiciones que conviven y que buscan imponerse, y es precisamente por la imposibilidad de triunfar de ninguna de ambas que se asiste a una suerte de tragedia. Debido a ello, resulta más preciso situarse en lo de indeterminado del drama, en eso que lo convierte en cuasi una tragedia: la tensión entre civilización y barbarie expresa un problema que, desde la óptica de Sarmiento, debe resolverse sin rodeos en favor de la civilización. Pero la complejidad del asunto estriba en el hecho de que como la barbarie no sólo no ha sido desterrada ni acabada para el momento en que el sanjuanino escribe, pues se siente orgullosa de sí y su poderío va en aumento, Sarmiento necesita analizarla y comprenderla, interpretarla y desmenuzarla en sus partes más entrañables e incluso en sus dimensiones encantadoras:

Sin ninguna instrucción, sin necesitarla tampoco, sin medios de subsistencia como sin necesidad, es feliz en medio de su pobreza y de sus privaciones, que no son tales para el que nunca conoció mayores goces, ni extendió más alto sus deseos; de manera que si esta disolución de la sociedad radica hondamente, la barbarie, por la imposibilidad y la inutilidad de la educación moral o intelectual, no deja, por otra parte, de tener sus atractivos ${ }^{\circ}$.

Sarmiento descubre el encanto de la vida del gaucho y de la vida social que la cultura de las campañas supo forjar: la intermitente relación con la muerte, la virilidad propia de quienes asiduamente se enfrentan a los peligros del llano; el uso del cuchillo como modo de enfatizar no necesariamente una doctrina de la muerte sino más precisamente una doctrina de la dominación:

\footnotetext{
4- Sarmiento, D.F. op. cit. Pág. 10

5- Hay que enfatizar que Sarmiento utiliza "y" y no "o", razón por la cual no sería del todo lícito pensar el asunto en términos excluyentes, aunque ése sea el objetivo político del autor. La convivencia entre ambos elementos configura un drama que Sarmiento necesita señalar como un obstáculo para los fines políticos que él persigue, pero en el tránsito de ese señalamiento el autor dio lugar, acaso sin notarlo, a una interpretación cuyas resonancias no parecen ir en la misma dirección que sus objetivos políticos.

6- Sarmiento, D.F. op. cit. Pág. 22.
} 
A la mayor señal de insubordinación, el capataz enarbola su chicote de fierro y descarga sobre el insolente golpes que causan contusiones y heridas; y si la resistencia se prolonga, antes de apelar a las pistolas, cuyo auxilio por lo general desdeña, salta del caballo con el formidable cuchillo en mano y reivindica bien pronto su autoridad por la superior destreza con que sabe manejarlo ${ }^{7}$.

El desdén por las pistolas y la preferencia por el cuchillo tal vez expliquen esa mixtura analítica, ese desdibujamiento del cual se habla en el comienzo de este trabajo, respecto del medio geográfico y del factor humano que en él se despliega. Lo que ese hombre necesita y busca, en el meollo de un contexto siempre amenazante, no es aniquilar completamente las amenazas, sino domeñarlas; no se trata, en efecto, de la destrucción total del otro, sino de la práctica del deseo antropógeno:

Todo deseo humano, antropógeno, generador de la Autoconciencia, de la realidad bumana, se ejerce en función del deseo de 'reconocimiento.' Y el riesgo de la vida por el cual se 'reconoce la realidad humana es un riesgo en función de tal Deseo. Hablar del 'origen' de la Autoconciencia implica por necesidad hablar de una lucha a muerte por el 'reconocimiento ${ }^{8}$.

(...) De nada sirve al hombre la luch a para matar a su adversario. Debe suprimirlo dialécticamente. Es decir, debe dejarle la vida y la conciencia y destruir sólo su autonomía. No debe suprimirlo sino en tanto que se le opone y actúa contra él. Dicho de otra manera, debe someterlo?.

Hay en torno de este asunto una discusión profunda acerca del monopolio de la fuerza. Discusión que está en el centro del problema de la organización nacional y que aqueja a Sarmiento y lo moviliza a desandar eso que rechaza pero que no le es de ningún modo ajeno. Sin embargo, como se decía anteriormente, en el transcurso de ese análisis, en el derrotero que Sarmiento traza sobre al vida de Facundo Quiroga, el escritor advierte una alteración en el orden de las cosas: alteración que anida en la imposibilidad de importar un modelo de civilización hacia el interior de una cultura que ha logrado cierto grado de autonomía respecto de la que se practica en la ciudad; y esa autonomía se funda, con todo lo que ello implica, en una simbiosis con el medio geográfico que lleva consigo la exaltación del uso de la fuerza, pero no para matar ni para destruir por mero goce mortífero, sino y exclusivamente para monopolizar ese control que todo Estado necesita para dar lugar a la organización ulterior: el control sobre el territorio a partir del monopolio legítimo de la fuerza, según la clásica definición weberiana ${ }^{10}$. En ese sentido, el control que ejerce el cuchillo del gaucho, la fuerza que brota de su dominio sobre el territorio y todo aquello que le rodea, es el mayor obstáculo al monopolio que necesita el Estado tal como se lo prefigura Sarmiento; esto es, al monopolio de la fuerza en clave moderna y organizada, que recién con Julio A. Roca se consolidará.

Así advertimos en Facundo el descubrimiento por parte de Sarmiento de que esa dicotomía política es, a su vez, una dicotomía cultural, y que ésta, por su parte, es un espejo de aquella. Este efecto especular no permite que el analista prescinda de las imágenes que el fenómeno proyecta sobre él, ni mucho menos el consecuente y ansiado enfoque sobre "el elemento central" que permitiría ese deslinde. Por el contrario, al ser un conflicto de aristas simultáneas pero sobre un territorio común, sus rasgos adquieren un tono dramático y trágico que le imprimen al mismo una impronta fatal: la civilización y la barbarie se disputan un terreno, pero ambas guardan antagónicas prácticas significantes que se reflejan tanto en la política como en la cultura.

\footnotetext{
Sarmiento, D.F. op. cit. Pág. 11

Kojève, A. La dialéctica del amo y del esclavo en Hegel, Buenos Aires: Leviatán, 2006. Pág. 14.

Kojève, A. op. cit. Pág. 22.

0- Weber, M. Economía y sociedad, México: FCE, 1964. Tomo I.
} 
Existe en Facundo una suerte de fascinación antropológica por parte de Sarmiento para con el rasgo autónomo, en el sentido estricto del término, de esa cultura que anida en los espacios no urbanos, no civilizados. Es este rasgo de autonomía lo que desespera a Sarmiento, debido a que como él conoce y ha experimentado el bienestar de la vida civilizada, tanto en sus dimensiones materiales como estéticas, además de haber estudiado a los autores europeos en boga, desea dar cuenta de la vida aldeana y pobre que esos gauchos llevan, quienes ignoran profundamente, según su interpretación, todo el bagaje cultual que desde Europa y América derrama sobre Buenos Aires, la ciudad por antonomasia:

Es preciso ver estas caras cerradas de barba, estos semblantes graves y serios, como los de los árabes, asiáticos, para juzgar del compasivo desdén que les inspira la vista del hombre sedentario de las ciudades, que puede haber leido muchos libros, pero que no sabe aterrar un toro bravio y darle muerte; que no sabrá proveerse de caballo a campo abierto, a pie y sin el auxilio de nadie (...) $)^{11}$

(...) Este hábito de triunfar de las resistencias, de mostrarse siempre superior a la naturaleza, de desafiarla y vencerla, desenvuelve prodigiosamente el sentimiento de la importancia individual y de la superioridad. ${ }^{12}$

En ese vínculo entre medio geográfico y vida cultural, Sarmiento redescubre la condición humana de los llanos, pero lo hace a través de la tendencia del hombre a organizarse y a ser, ontológicamente, de un modo específico bajo determinaciones símiles:

En fin, otros mil accidentes que omito prueban la verdad de que modificaciones análogas del suelo traen análogas costumbres, recursos y expedientes. No es otra la razón de hallar en Fenimore Cooper descripciones de usos y costumbres que parecen plagiadas de la pampa; así, hallamos en los hábitos pastoriles de la America, reproducidos, hasta los trajes, el semblante grave y hospitalidad árabes. ${ }^{13}$

Si bien es muy atinado el análisis de Ana María Barrenechea acerca de la influencia de la estética romántica en la interpretación que Sarmiento hace de Quiroga, a quien elige en lugar de Rosas como protagonista de su obra, esa influencia del romanticismo no excluye el hecho de que Sarmiento se viera fascinado por lo que observa, en un sentido no necesariamente apologético (ni tampoco peyorativo).

Sarmiento se encuentra deslumbrado por la indiferencia y aun por el rechazo que la cultura del campo profesa respecto de la gran cultura de la civilización que él busca tenazmente instaurar como modelo para la Argentina, y en la medida en que el texto avanza en sus detalles se percibe cómo el factor trágico que de a momentos se presenta o bajo la crítica descarnada o bajo el asombro inusitado que bordea la admiración no reconocida, toma de cuerpo a Sarmiento, quien finalmente resuelve su inclinación por la civilización de un modo especular: se sirve de la fuerza y del vigor que, como un alquimista, parece extraer del objeto de su estudio, y aplica por sobre el mismo una fiereza cuya potencia pareciera provenir no necesariamente de la civilización que en el texto se describe y se presenta como el horizonte buscado, sino de una barbarie ínsita en su vehemencia efusiva. 


\section{La poesía y una aparente supresión de la lógica especular en Facundo}

Acaso en la poesía Sarmiento encuentre un elemento para conjurar la tensión entre civilización y barbarie. No es del todo seguro que así sea, pero se deja entrever en sus apreciaciones una tendencia a considerar el carácter poético del pueblo argentino:

Así, pues, en medio de la rudeza de las costumbres nacionales, estas dos artes, que embellecen la vida civilizada y dan desahogo a tantas pasiones generosas, están honradas y favorecidas por las masas mismas, que ensayan su áspera musa en composiciones líricas y poéticas. El joven Echeverría residió algunos meses en la campaña en 1840, y la fama de sus versos sobre la pampa le habia precedido ya; los gauchos lo rodeaban con respeto y afición, y cuando un recién venido mostraba señales de desdén hacia el cajetilla, alguno le insinuaba al oído: 'Es poeta', y toda prevención hostil cesaba al oír este titulo privilegiado ${ }^{14}$

En la poesía, Sarmiento descubre que existe un nexo, un territorio simbólico que por momentos es categorizado como: "una facultad del espíritu humano" que "necesita del espectáculo de lo bello". Sin embargo, lo brillante de este fragmento de Facundo es que no parece quedar del todo clara la verdadera posición del autor:

La poesia para despertarse, porque la poesia es, como el sentimiento religioso, una facultad del espiritu humano, necesita el espectáculo de lo bello, del poder terrible, de la inmensidad de la extensión, de lo vago, de lo incomprensible, porque sólo donde acaba lo palpable y vulgar empiezan las mentiras de la imaginación, el mundo ideal. ${ }^{15}$

Si la poesía se encuentra atada a lo bello, y si este carácter poético del pueblo argentino es, por su parte, un aspecto creativo y una suerte de dote, a su vez también da lugar a las mentiras de la imaginación; y si bien Sarmiento se encarga de establecer diferencias entre la poesía culta y "la poesía desaliñada" del gaucho, no deja de reconocer que éste, cuando se presenta un poeta (como en el caso de Echeverría) sabe respetar la investidura que, por lo demás, no clausura al sujeto incluso cuando este provenga de la cultura ilustrada.

La desterritorialización de la poesía, que opera en un mundo simbólico y onírico que en el caso del gaucho se expresa también en la música, en lo triste, en la vidalita, tal vez sea la razón por la cual el conflicto por el monopolio de la fuerza en el territorio es conjurado: aun cuando a través de la poesía se ensalcen las proezas de la guerra, sus pliegues permiten, precisamente por su distancia respecto de las miserias terrenales, ingresar en ese ámbito no necesariamente sacro pero sí escindido del entramado inmediato de la política: la parte superior del pliegue no admitiría, entonces, el conflicto por el monopolio de la fuerza sobre el territorio en disputa, y al ser un espacio de proyecciones imaginarias, la tensión entre civilización y barbarie podría conjurarse; la lógica especular se disiparía porque el simbolismo de la poesía condensaría en sí las proyecciones imaginarias, dejando de lado el conflicto territorial (a su vez terrenal).

\section{La autoridad como fundamento de la Nación}

Si a partir del análisis de la poética nacional que Sarmiento efectúa podría permitirse el lector una interpretación que conjure, como se dijo, el conflicto en el territorio, la aparición cruda de la política, que en los capítulos de la Parte Segunda toma un curso concreto, reintroduce en el texto la variable ideológica: el factor político triunfa sobre todos los otros, y el juego de espejos que parecía guiar

14- Sarmiento, D.F. op. cit. Pág. 29

15- Sarmiento, D.F. op. cit. Pág. 25. 
la mimética relación entre cultura y política finalmente se rompe, aunque sólo imaginariamente (pues Sarmiento, en ese juego, opta por una de las representaciones sin ser plenamente consciente de ello, esto es, de que su postura responde, al fin y al cabo, a una imagen transfigurada en dogma viva entre otras imágenes: la de los gauchos, por ejemplo, y su autonomía cultural), pero de un modo suficiente como para que Sarmiento se sacuda el polvo deliberativo que antes fuera el recipiendario de su talante democrático, cuando se acongojaba de que "el predominio de la fuerza brutal, la preponderancia del más fuerte, la autoridad sin límites y sin responsabilidad de los que mandan" dieran lugar a una justicia que se administra "sin formas y sin debate", para inclinarse por la centralización y la supresión de toda deliberación y así dar lugar al establecimiento definitivo de la autoridad:

A estos elementos de antagonismo se añadía otra causa no menos grave; tal era el aflojamiento de todo vínculo nacional, producido por la revolución de la Independencia. Cuando la autoridad es sacada de un centro para fundarla en otra parte, mucho tiempo antes de echar raíces. El Republicano decía el otro día que la autoridad no es más que un convenio entre gobernantes y gobernados.' ; Aqui hay muchos unitarios todavia! La autoridad se funda en el asentimiento indeliberado que una nación da a un hecho permanente. Donde hay deliberación y voluntad no hay autoridad. ${ }^{16}$

Aquí Sarmiento define, y así lo hará en lo que resta del texto, la exaltación de la autoridad, elemento central y necesario para la consolidación de la nación, que a través de la figura de Paz, "hijo legítimo de la ciudad, el representante más cumplido del poder de los pueblos civilizados"17 , "militar a la europea", espíritu guerrero de la Europa cristalizará la figura necesaria para consolidar el proyecto que Sarmiento considera propicio para la Argentina.

Si el entrecruzamiento entre condición humana y naturaleza atribuía, según Sarmiento, un carácter específico a quienes vivían en determinado medio geográfico, carácter que, por cierto, se haría en torno de la violencia y de la barbarie, el uso de la fuerza por parte de un general a la europea, como ocurre en el caso de Paz, estaría legitimado por la ruptura del juego especular: ya lo europeo adquiere en este momento del texto una superioridad moral, estética, filosófica, y lo humano puede interpretarse, entonces, como la evocación de la voluntad de mandar, del atributo de la obediencia y de la autoridad que si bien puede legitimarse a través de una perspectiva moral, filosófica e incluso estética, no por eso es más legítima que las otras: como se señala en el título de este ensayo, Facundo se posiciona aquí entre la naturaleza y la condición humana, pero esa naturaleza ya deja de ser la naturaleza material del medio geográfico, y pasa a ser, por su parte, esa abigarrada concepción entendida como "naturaleza humana".

No falta fragmento en Facundo en el que Sarmiento palpite este elemento, pero lo que para el objeto de este trabajo resulta relevante no se reduce a si Sarmiento adhiere a alguna de las tantas concepciones acerca de la naturaleza humana: interesa destacar que si la relación entre naturaleza y condición humana dotaban a esa cultura de las campañas de una suerte de barbarie por estar entretejida en medio de la violencia: entiéndase, de la violencia destinada a domeñar, tal como se dijo anteriormente, en el caso de la legitimación de la violencia por parte de la civilización encarnada por Paz, el destino es exactamente el mismo: dominar, sentar las bases, a través de la violencia, de la Nación, y es precisamente en este sentido que Facundo se encuentra entre la naturaleza y la condición humana, entendida la primera en sus dos acepciones: naturaleza como medio geográfico que podría influir en el comportamiento humano, y naturaleza en el sentido político, que consiste en elaborar una fórmula política ${ }^{18}$, tal como concibiera Mosca, que permita legitimar el dominio que un sector de la sociedad ejerce sobre el resto. En ese sentido, la naturaleza, ya no material, ya no geográfica, ya no vegetal, ya no la fauna ni la flora, sino la naturaleza eminentemente política del hombre, conduce la trama argumentativa que Sarmiento despliega lúcida y tenazmente a lo largo de todo el libro: Facundo, civilización y barbarie, también puede leerse como Facundo, el proyecto latente de la civilización y el proyecto latente de la barbarie, esto es,

16- Sarmiento, D.F. op. cit. Pág. 105.

17- Sarmiento, D.F. op. cit. Pág. 134

18- Según Gaetano Mosca, la fórmula política es la justificación moral, legal o de otra índole que le permite a la clase política consolidar el ejercicio monopólico del poder que lleva a cabo, ya que, según nuestro autor, no es suficiente poseer el poder de facto: además de esto, es necesario legitimarlo. Por lo tanto, Mosca indica que la fórmula política es una "base jurídica y moral" diferente en cada sociedad. 
como una disputa entre dos modos de construirse que tiene el dominio: de un lado, racional, europeo y estéticamente delineado, de otro, abigarrado, autónomo y en consonancia con el entorno medioambiental.

Desde ya, esto no debería inducirnos a pensar, romántica o racionalmente, que uno u otro proyecto era el "ideal". El objetivo de estas reflexiones es indagar en cómo la autoridad siempre se construye sobre la base de premisas estéticas, filosóficas y culturales, y persistir, entonces, en la siempre dudosa pero latente cuestión que existe en torno de la existencia, o no, de la naturaleza humana, que, citando a Kojève, aquí se entiende como el deseo de reconocimiento y de dominación, y que un sentido clásico, tal como se ha citado en el caso de Mosca, pero también como lo entiende Weber y gran parte de la filosofía política, puede entenderse como los modos a partir de los cuales una dominación de facto deviene legal (ya sea en un sentido moderno, a través del carisma, de la tradición, o mediante una mixtura entre estos elementos, que pocas veces suelen presentarse en estado puro). 


\section{Referencias bibliográficas}

Altamirano, C., Sarlo, B. (1997). Ensayos argentinos. De Sarmiento a la Vanguardia. Buenos Aires: Ariel.

Barrenechea, A.M. (1978). "Función estética y significación histórica de las campañas pastoras en el Facundo", en: Textos hispanoamericanos. Caracas: Monte Ávila Editores.

Kojève, A. (2006). La dialéctica del amo y del esclavo en Hegel, Buenos Aires: Leviatán.

Mosca, G. (2004). La clase política. México: FCE.

Piglia, R. (1980). "Notas sobre Facundo", en: Punto de Vista, W 8.

Sarmiento, D.F. (193S). Facundo, civilización y barbarie. Colección "Letras de Oro". Buenos Aires: M. Alfredo Angulo Editor.

Weber, M. (1964). Economía y sociedad, Tomo I. México: FCE 